\title{
Geociências
}

\section{Caracterização petrográfica e aspectos diagenéticos dos arenitos do Grupo Bauru na região sudoeste do Estado de São Paulo}

\author{
(Petrography and diagenetic aspects of the Bauru Group \\ sandstones in the southwestern region of the São Paulo State)
}

\author{
Marcia Regina Stradioto \\ Geóloga / Mestre (Geociências e Meio Ambiente) - Universidade Estadual Paulista - UNESP \\ E-mail:marciastradioto@uol.com.br \\ Chang Hung Kiang \\ Professor, Dr., Departamento de Geologia Aplicada da Universidade Estadual Paulista - UNESP \\ E-mail:chang@rc.unesp.br \\ Maria Rita Caetano-Chang \\ Professora, Dra., Departamento de Geologia Aplicada da Universidade Estadual Paulista - UNESP \\ E-mail:mrchang@rc.unesp.br
}

\section{Resumo}

Esse trabalho apresenta a caracterização petrográfica e diagenética de arenitos pertencentes ao Grupo Bauru, tendo como material de estudo testemunhos de sondagem extraídos de um poço-pesquisa de 250m de profundidade, perfurado no município de Pirapozinho, região sudoeste do Estado de São Paulo. O estudo envolveu a utilização de microscopia óptica e microscopia eletrônica de varredura. $\mathrm{O}$ arcabouço detrítico desses arenitos é constituído essencialmente por quartzo e feldspatos e, em menor quantidade, por fragmentos líticos e minerais acessórios. Os arenitos do Grupo Bauru apresentam evidências de processos eodiagenéticos. Os principais processos diagenéticos observados foram: dissolução de minerais pesados, fragmentos líticos e aluminossilicatos; cimentação por calcita microcristalina; formação de argilominerais; cimentação poiquilotópica de calcita; e cimentação por zeólitas.

Palavras-chave: Petrografia, diagênese, Grupo Bauru.

\begin{abstract}
This work presents a petrographic and diagenetic study of the Bauru Group sandstones. Core samples were collected from a 250m-deep well located in the City of Pirapozinho, southwestern region of State of São Paulo. Optical and scanning electron microscopy were applied to these studies. The detrital composition of these sandstones is constituted essentially by quartz and feldspars and in minor amounts by rock fragments and accessory minerals. The sandstones of Bauru Group underwent eodiagenesis. The main diagenetic processes identified are: dissolution of heavy minerals, rock fragments and aluminossilicate mineral; microcrystalline calcite cementation; formation of clay minerals; poikilotopic calcite cementation; and zeolite cementation.
\end{abstract}

Keywords: Petrography, diagenesis, Bauru Group. 


\section{Introdução}

O Grupo Bauru compreende uma sucessão de rochas sedimentares cretáceas depositadas na porção centro-setentrional da bacia do Paraná, sobre substrato constituído por rochas basálticas da Formação Serra Geral e, localmente, sobre os sedimentos das formações Botucatu e Pirambóia, como na região de Bauru (SP) e Agudos (SP) (Suguio et al.,1977 e Paula e Silva \& Cavaguti, 1994).

O Sistema Aqǘffero Bauru representa uma das principais fontes de exploração de águas subterrâneas no Estado de São Paulo. Entre os 462 municípios paulistas que são abastecidos, parcial ou integralmente, por água subterrânea, aproximadamente $59 \%$ captam água do Sistema Aqüífero Bauru, sendo que, em 88\% deles, o abastecimento é feito exclusivamente por água subterrânea (CETESB, 1997).
Segundo Barison (2003), os arenitos do Grupo Bauru, coletados em afloramentos, na porção meridional do Sistema Aquúfero Bauru, no Estado de São Paulo, são classificados predominantemente como quartzo arenitos; Batezelli et al. (2005), em estudo realizado no Triângulo Mineiro (MG) e partes da região nordeste do Mato Grosso do Sul e sul de Goiás, classificam os arenitos do Grupo Bauru como litoarenitos e litoarenitos feldspáticos.

O objetivo desse trabalho foi caracterizar petrograficamente os arenitos que constituem o Sistema Aqüífero Bauru, examinando os aspectos composicional e diagenético dessas rochas-reservatório. O material utilizado provém de testemunhos de sondagem de um poço de 250m, perfurado no município de Pirapozinho. Nesse poço-pesquisa, foram identificadas as unidades que ocorrem na região sudoeste do Estado de São
Paulo - formações Caiuá, Pirapozinho, Santo Anastácio, Araçatuba e Adamantina. A nomenclatura estratigráfica aqui adotada segue a estabelecida por Paula e Silva (2003) e Paula e Silva et al. (2005).

\section{2. Área de estudo}

A área de estudo localiza-se na região sudoeste do Estado de São Paulo, englobando as cidades de Presidente Prudente, Pirapozinho e Regente Feijó (Figura 1). Na área, afloram rochas da Formação Adamantina, unidade superior do Grupo Bauru na região.

As rochas do Grupo Bauru são constituídas predominantemente por sedimentos siliciclásticos continentais que foram depositados na porção centro-sul da Plataforma Sul-Americana, durante o último episódio significativo de sedimentação da bacia do Paraná. Litologicamente, essa sucessão é caracte-

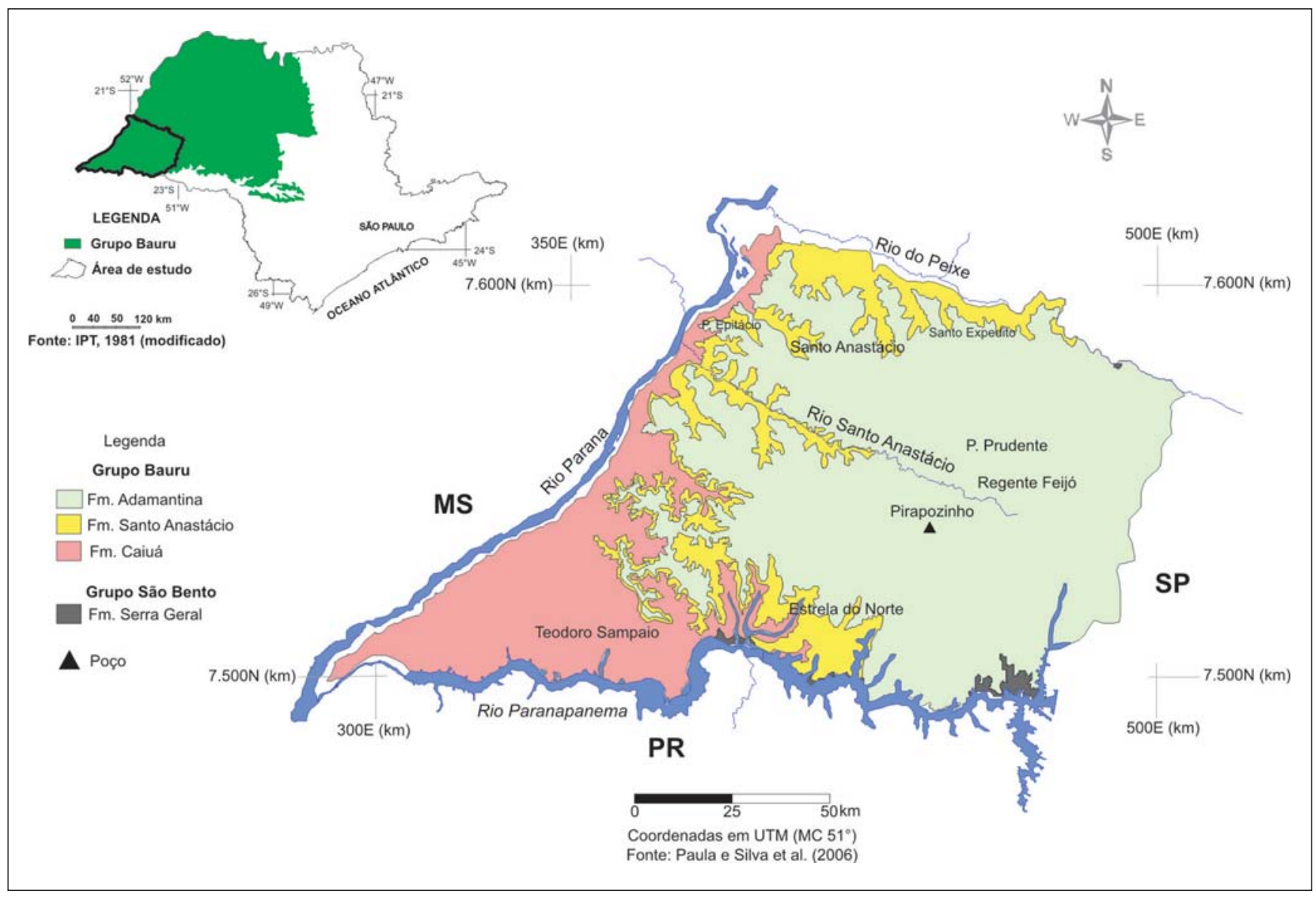

Figura 1 - Mapa de localização da área estudada e ocorrência do Grupo Bauru (Modificado de IPT, 1981). 
rizada por arenitos, arenitos argilosos, carbonáticos ou não, siltitos, lamitos e argilitos, apresentando localmente conglomerados e camadas calcárias (DAEE, 1976).

Coube a Soares et al. (1980) a primeira subdivisão estratigráfica formal do Grupo Bauru, que distinguiu as formações Caiuá, Santo Anastácio, Adamantina e Marília, com base em suas características litológicas e genéticas. A litofácies Araçatuba, inicialmente reconhecida por Suguio et al. (1977), foi redefinida e incorporada definitivamente ao Grupo Bauru por Batezelli et al. (1999).

Estudos de subsuperfície realizados por Paula e Silva (2003) e Paula e Silva et al. (2005, 2006) mantiveram a subdivisão proposta por Soares et al. (1980), com inclusão da Formação Araçatuba, e formalização das formações Pirapozinho e Birigui, identificadas com base em perfis geofísicos e descrição de amostras de calhas.

\section{Materiais e métodos}

Uma vez que na área de estudo afloram somente os arenitos da Formação Adamantina, estando as demais unidades do Grupo Bauru restritas à subsuperfície, as amostras aqui utilizadas foram coletadas de testemunhos de sondagens de um poço de pesquisa, de 250m de profundidade, perfurado no município de Pirapozinho-SP (Figura 1). Foram selecionadas 88 amostras para caracterização petrográfica, oriundas das diferentes unidades do Grupo Bauru atravessadas pela sondagem - formações Caiuá, Santo Anastácio, Araçatuba e Adamantina.

As amostras selecionadas para caracterização petrográfica foram impregnadas pelo método de Cesero et al. (1989), para confecção de lâminas delgadas, e foram, em seguida, analisadas por meio de microscopia óptica e eletrônica de varredura. A análise de microscopia eletrônica foi efetuada no ED-SEM Energy Dispersive Scanning Electron Microscope, Modelo LEO 430, com detectores de elétrons secundários e retroespelhados
(Backscattered). A microscopia óptica visou, basicamente, à descrição da composição mineralógica e textural dos arenitos. Os aspectos texturais analisados foram a granulometria, a forma e o arredondamento dos grãos. Foram efetuadas, também, contagens de grãos do arcabouço, cimento, matriz e porosidade. Do testemunho de sondagem, foram coletadas 49 amostras, que foram submetidas à análise de difração de raios $\mathrm{X}$, efetuada no espectrômetro Siemens D5000 com goniômetro de textura acoplado, e interpretadas com o uso do software Siemens Diffracplus D-5000-1997.

Na análise da composição mineral dos grãos detríticos, foi utilizada a classificação de Folk (1968), com base no conteúdo total de quartzo, feldspato e fragmentos líticos.

\section{Resultados e discussões Classificação e textura dos arenitos estudados}

Devido à baixa recuperação de testemunhos de sondagem das formações Adamantina e Araçatuba, foram analisadas apenas 8 amostras de arenitos dessas unidades, sendo 6 da primeira e 2 da segunda. Esses arenitos mostram granulometria com predomínio das classes fina e muito fina e seleção média.

A boa recuperação de testemunhos da Formação Santo Anastácio permitiu a seleção de 50 amostras entre as profundidades de 92 e 166 metros. Os arenitos dessa unidade apresentam granulometria variando de média a muito fina, com predomínio da classe fina, e seleção variando de boa a ruim.

Da Formação Caiuá, foram selecionadas 30 amostras entre as profundidades de 188 e 242 metros. A granulometria dos arenitos da unidade varia entre média a muito fina, com predomínio das classes fina e média, e seleção variando de boa a média.

Em todas as formações, os grãos variam entre subarredondados e suban- gulares, com o arcabouço sedimentar apresentando matriz argilosa em quantidade inferior a $10 \%$ em todas as amostras. Do ponto de vista textural, os arenitos são classificados predominantemente como submaturos.

A porosidade do tipo intergranular é mais freqüente em todas as lâminas; secundariamente, ocorrem porosidades do tipo intragranular. A porcentagem média estimada de porosidade foi de $17 \%$, sendo que as formações Adamantina e Araçatuba apresentaram os menores valores, $12 \%$ e $14 \%$ respectivamente, seguidas das formações Caiuá (16\%) e Santo Anastácio (18\%). Nas amostras analisadas, não foi observada clara tendência no comportamento da porosidade com a profundidade. A variação está associada à cimentação dos poros, em diferentes níveis, conforme constatado com freqüência nas lâminas petrográficas. Essa situação está ilustrada na Figura 2, onde se observam amostras com elevada porosidade (Fotos A, C, E e $G$ ) e outras muito cimentadas (Fotos B, D e F).

Segundo o critério de Folk (1968), os arenitos das formações Adamantina e Araçatuba são classificados como subarcóseos, ocorrendo somente uma amostra de arcóseo da Formação Adamantina. Os arenitos da Formação Santo Anastácio são todos subarcóseos, enquanto os arenitos da Formação Caiuá correspondem a subarcóseos e, secundariamente, a arcóseos (Figura 3).

\section{Arcabouço mineralógico dos arenitos do Grupo Bauru}

Os arenitos do Grupo Bauru, na área de estudo, apresentam composição mineralógica rica em quartzo monocristalino; apenas 5 lâminas apresentam quartzo policristalino, sendo 2 da Formação Santo Anastácio e 3 da Formação Caiuá, porém, mesmo nessas lâminas, a ocorrência é rara. A porcentagem média de quartzo entre os minerais identificados é de $81,4 \%$ na Formação Adamantina, 85,4\% na Formação Araçatuba, 84,3\% na Formação Santo Anastácio e 80,8\% na Formação Caiuá. 
Os feldspatos são freqüentes em todas as lâminas petrográficas examinadas, sendo representados principalmente por ortoclásio, microclina e plagioclásio. Em algumas amostras, esses minerais estão bastante alterados, apresentando porosidade intragranular bem desenvolvida. A porcentagem média de feldspatos encontrada é de 16,2\%; a maior ocorrência foi registrada na Formação Caiuá (18,3\%), seguida das formações Adamantina (18,0\%), Santo Anastácio (14,8\%) e Araçatuba (14,2\%).

Fragmentos líticos, compostos predominantemente por intraclastos de argila e fragmentos de rochas ígneas, foram identificados em pequenas quantidades nas lâminas, perfazendo em média $0,90 \%$ dos constituintes das amostras.

O percentual médio de ocorrência de minerais acessórios é de 1,78\%. Os minerais mais comuns observados foram zircão, ilmenita e augita, este último bastante alterado; em menor quantidade aparecem apatita e cromita.

A matriz é constituída predominantemente por argilominerais do tipo ilita e montmorilonita e, em menor quantidade, por caulinita (Figura 4). Os argilominerais aparecem ocupando o espaço poroso e muitas vezes o espaço de grãos alterados, diminuindo a porosidade dos arenitos. A quantidade de matriz é variável dentro da mesma unidade.

\section{Processos diagenéticos}

A diagênese compreende os processos físicos, bioquímicos e químicos atuantes sobre os sedimentos após a deposição, em geral promovendo sua litificação, excluindo-se processos de metamorfismo (Morad, 1991). O campo da diagênese, subdividido em eodiagênese, mesodiagênese e telodiagênese, estende-se desde a superfície até cerca de 5 a $7 \mathrm{~km}$ de profundidade, em geral abrangendo variações de 21 a $200^{\circ} \mathrm{C}$ de temperatura e 1 a 2000atm de pressão (Schmidt \& Mcdonald, 1979 apud Wilson, 1994).

Os arenitos do Grupo Bauru estudados foram submetidos a uma diagê-

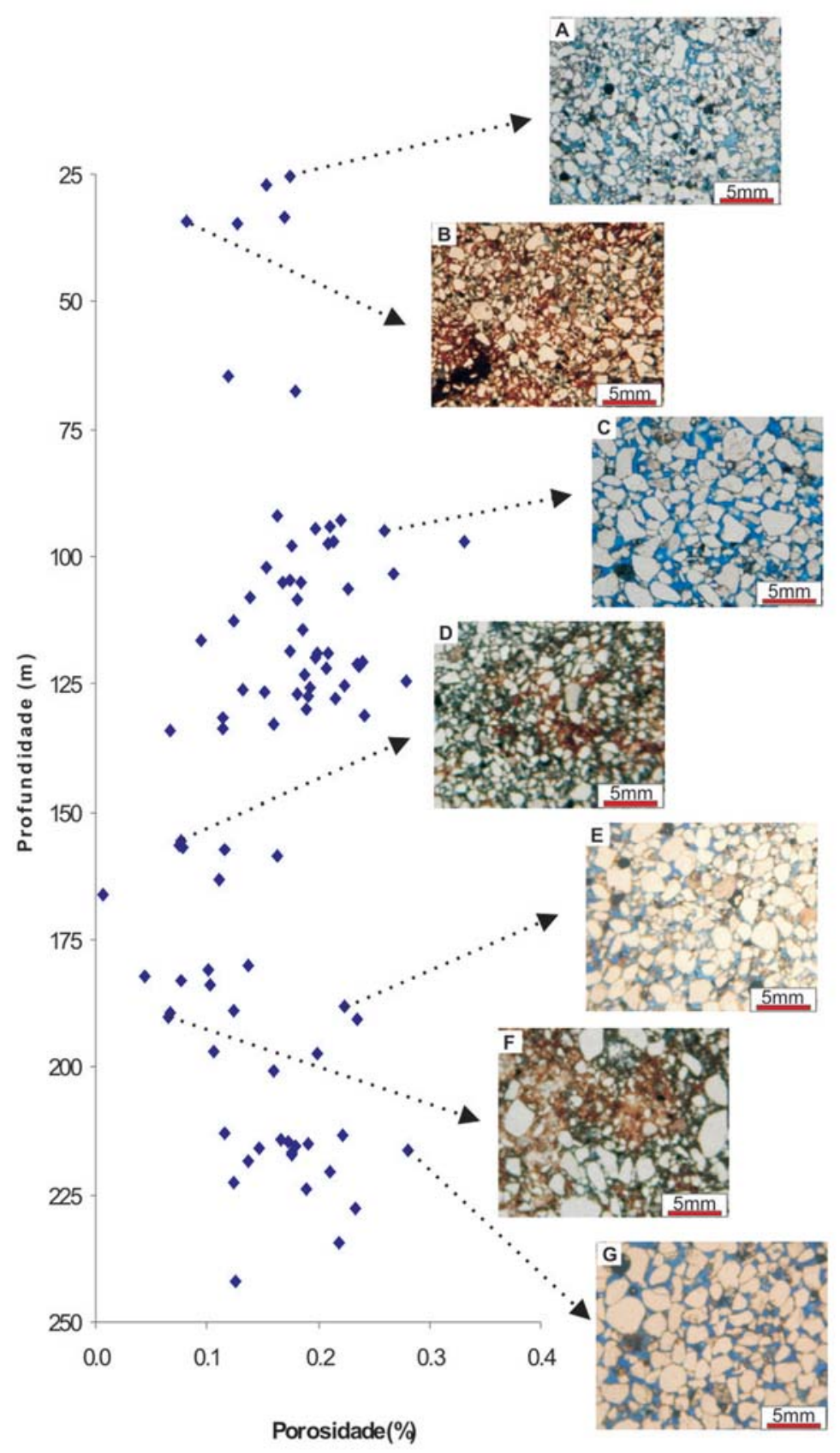

Formação Adamantina: fotos A e B

Formação Santo Anastácio: fotos C e D

Formação Caiuá: fotos E, F e G

Figura 2 - Gráfico da porosidade versus profundidade de amostras em poço perfurado em Pirapozinho-SP (Azul = poros).

nese rasa e pouco intensa. A eodiagênese, única fase presente nesses arenitos estudados, foi caracterizada por pequena compactação mecânica; cimentação por óxido e hidróxido de ferro, carbonatos e zeólitas; dissolução de minerais detríticos e formação de argilominerais. Os eventos diagenéticos a que foram submetidos os sedimentos do Grupo Bauru, descritos a seguir, compreendem processos de eodiagênese precoce a tardia. 


\section{Dissolução dealuminossilicatos, minerais pesados e fragmentos líticos}

A dissolução de grãos foi observada em arenitos de todas as formações estudadas, sendo mais freqüente na Formação Caiuá. Os minerais pesados, principalmente augita e ilmenita, que aparecem em abundância entre os minerais acessórios, estão bastante alterados. A dissolução desses minerais ocorre de forma precoce nesses sedimentos, liberando principalmente íons de $\mathrm{Ca}^{2+}$ e Fe.

Os fragmentos líticos, embora em pequena quantidade, aparecem em todas as formações estudadas. A dissolução desses fragmentos, principalmente de origem vulcânica, contribui para a liberação de íons como $\mathrm{Fe}$ e $\mathrm{Na}^{+}$.

A dissolução de silicatos, que ocorre com maior freqüência nos sedimentos estudados, aparece principalmente afetando os grãos de feldspatos. A dissolu-

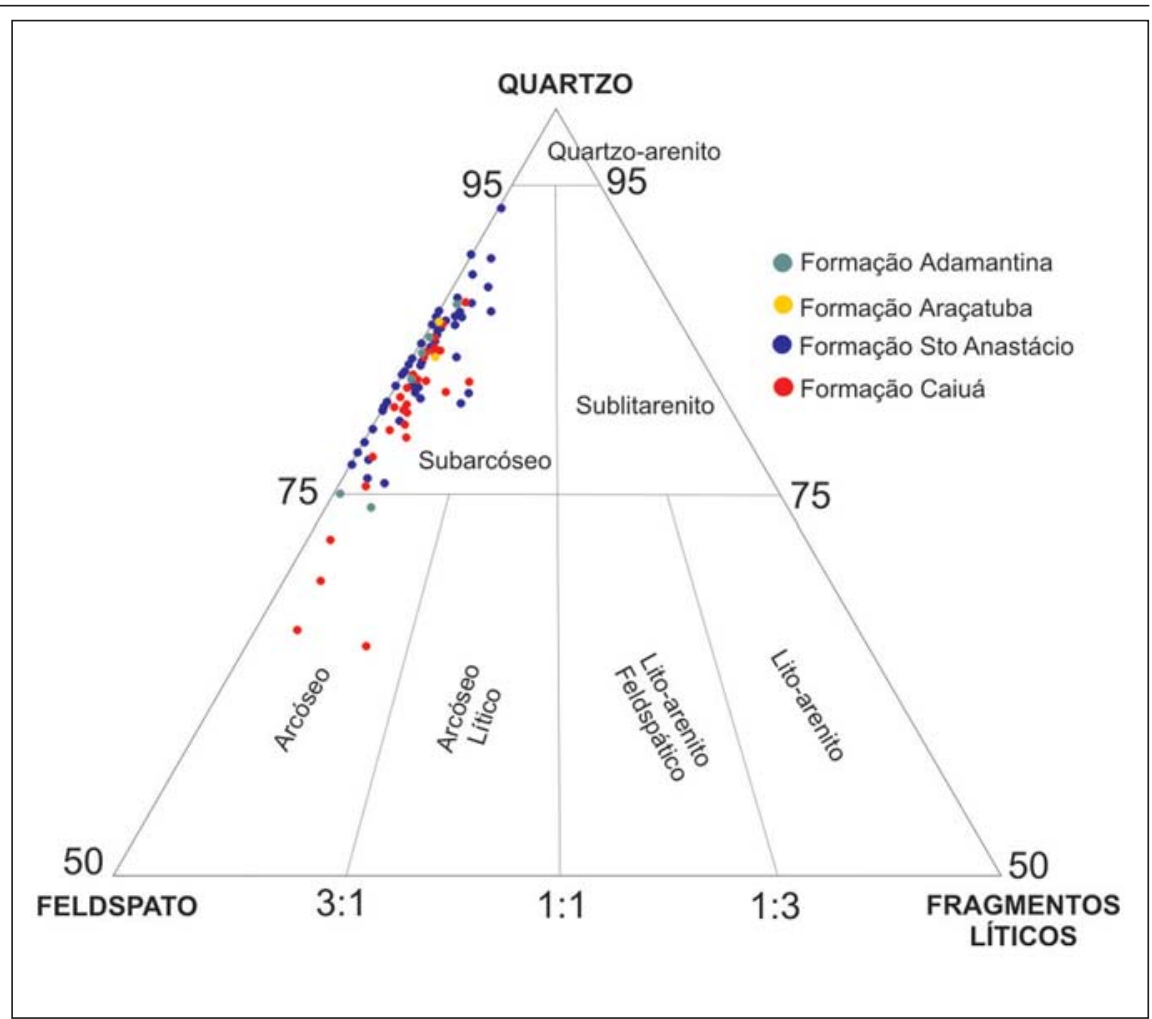

Figura 3 - Composição dos arenitos estudados, utilizando Diagrama de Folk (1968).

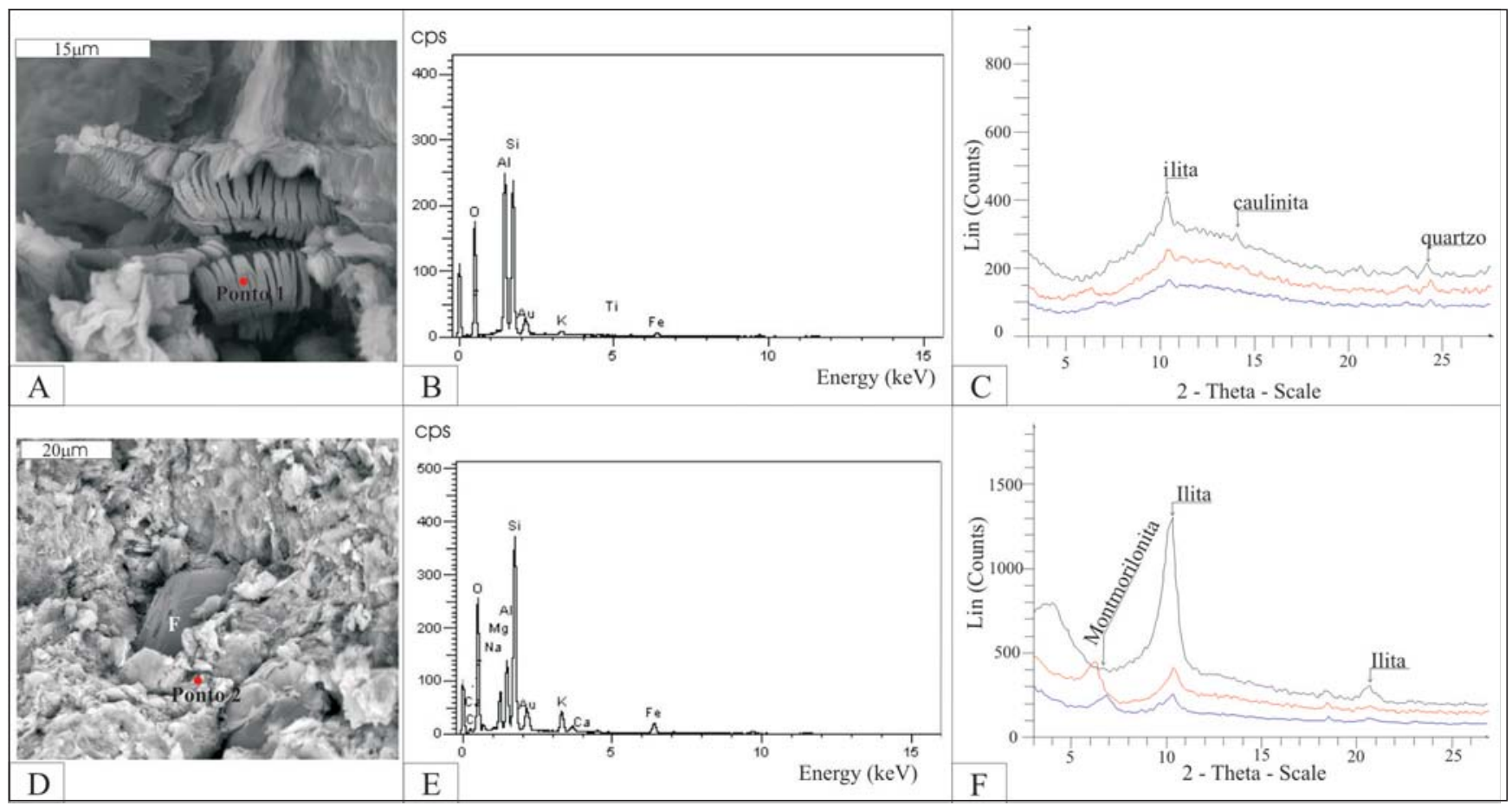

Figura 4 - A: Fotomicrografia de caulinita da Formação Caiuá (MEV); B: Análise semiquantitativa da caulinita, por meio de EDX, no

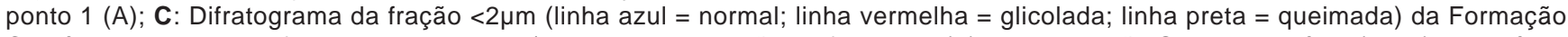
Caiuá; D: Fotomicrografia de montmorilonita/ilita envolvendo grão de feldspato (F), da Formação Santo Anastácio (MEV); E: Análise semiquantitativa da montmorilonita/ilita, por meio de EDX, no ponto 2 (D); e F: Difratograma da fração <2 $\mu$ m (linha azul = normal; linha vermelha = glicolada; linha preta $=$ queimada) da Formação Santo Anastácio. 
ção desses minerais pode liberar quantidade significativa de $\mathrm{Si}^{4+}, \mathrm{Al}^{3+}, \mathrm{K}^{+}, \mathrm{Na}^{+}$e $\mathrm{Ca}^{2+}$ nos fluidos dos poros. Além da liberação de íons, a dissolução gera a porosidade secundária, que foi encontrada com freqüência nas amostras estudadas (Figura 5).

\section{Precipitação de cimento ferruginoso}

Na maioria das amostras, foi constatada cimentação ferruginosa por goetita e/ou limonita, estando os grãos, às vezes, recobertos por uma fina película de coloração acastanhada. Essa cimentação aparece em todas as formações, porém, em alguns intervalos, com maior concentração de matriz, essa cimentação torna-se menos expressiva.

A dissolução de minerais pesados, descrita no item anterior, pode contribuir significativamente para a precipitação de óxidos e hidróxidos de ferro, como também para o aumento da concentração de íons de Fe e Mg em solução.

\section{Argilominerais}

A ocorrência de argilominerais é comum em todas as profundidades, aparecendo em todas as formações estudadas. Os argilominerais mais freqüentes são ilita e montmorilonita.

Esses argilominerais são em geral diagenéticos, embora sua origem, se detrítica ou diagenética, seja por vezes difícil de determinar; muitas vezes ocorrem preenchendo poros e envolvendo grãos do arcabouço (Figura 6).

\section{Compactação mecânica}

A compactação mecânica nesses arenitos é de baixa intensidade, uma vez que foram submetidos a pequeno soterra- mento. Na análise das lâminas de arenito, foram observados predominantemente contatos pontuais entre grãos e, raramente, contatos planares.

\section{Calcita}

A cimentação carbonática aparece na maioria das lâminas analisadas, onde ocorrem preenchendo vazios intergranulares e também substituindo parcialmente os grãos dissolvidos (Figura 7).

No presente estudo, foram identificados vários tipos de cimentos carbonáticos como calcita microcristalina (Figura 7B) e calcita em mosaico ou poiquilotópica (Figura 7A).

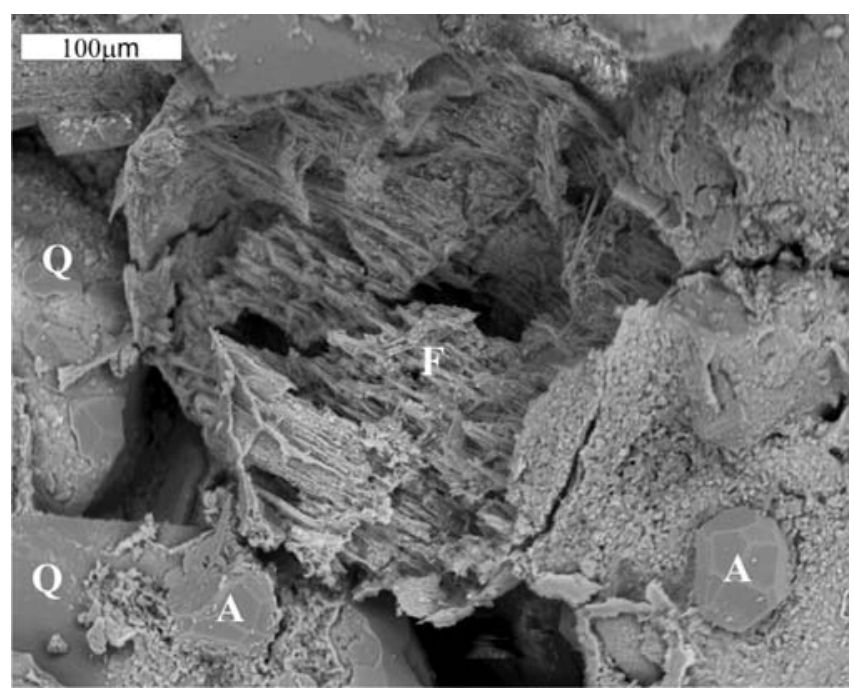

Figura 5 - Feldspato com evidência de dissolução na Formação Caiuá (Fotomicrografia de MEV). F=feldspato, $Q$ = quartzo, $\mathrm{A}=$ analcima .

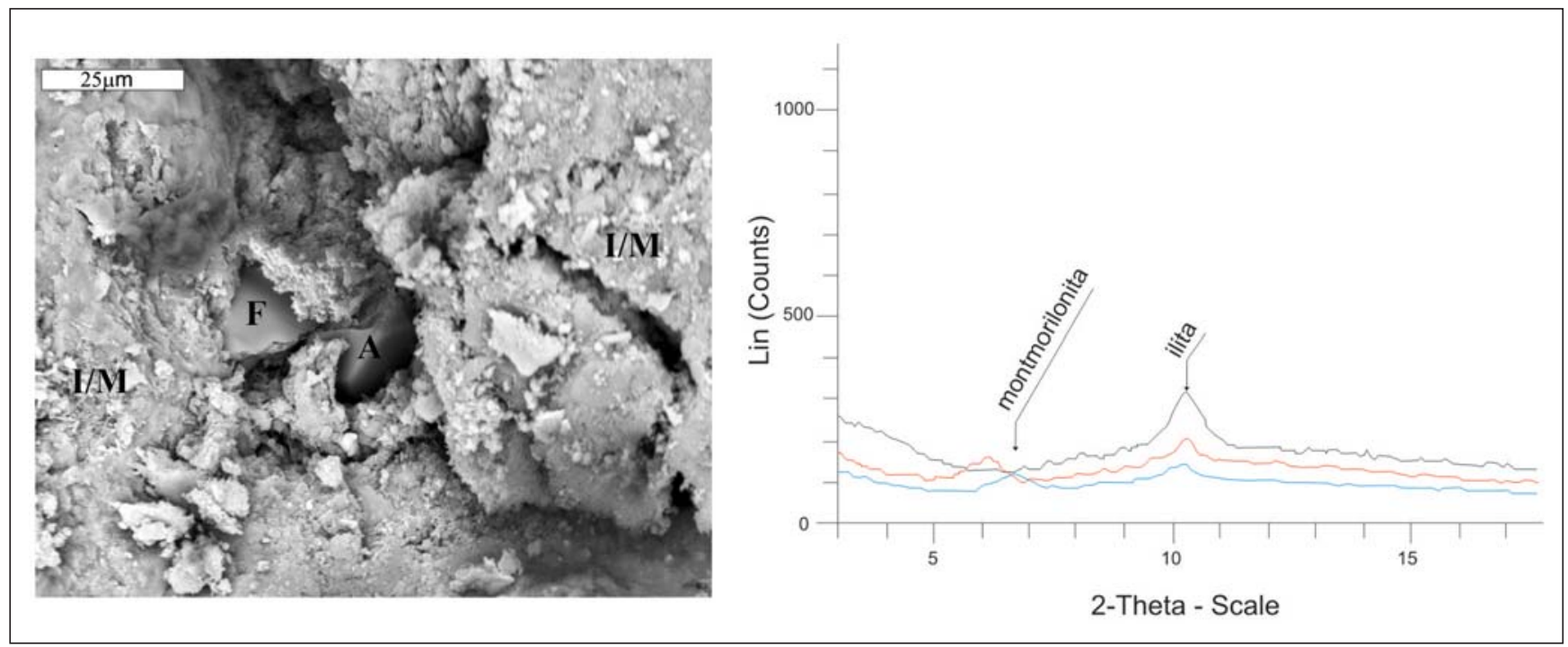

Figura 6 - Ilita/montmorilonita (I/M) envolvendo grãos de analcima (A) e feldspato (F) (Fotomicrografia de MEV) e difratograma da fração $<2 \mu \mathrm{m}$ (linha azul = normal; linha vermelha = glicolada; linha preta = queimada) - Formação Santo Anastácio. 
Os cimentos microcristalinos formam-se em uma fase mais precoce como cristais esféricos e micrométricos, possivelmente relacionados à geração de calcretes, na forma de concreções esféricas e dimensões milimétricas (Figura 7C).

A calcita em mosaico ou poiquilotópica ocorre preenchendo os poros dos arenitos e, às vezes, ocupando espaços de minerais dissolvidos. Essa fase é um pouco mais tardia em relação à calcita microcristalina. Também foi observada a cristalização de calcita bem formada, muitas vezes associada a zeólitas (Figura 7D). Segundo Hay (1966 apud Morad, 1991), a analcima precipita juntamente com a calcita sob condições de alta pressão parcial de $\mathrm{CO}_{2}$, em um sistema que normalmente precipitaria analcima sódica-cálcica. Essa calcita pode ser formada pela supersaturação no local, causada por dissolução de cimentos carbonáticos anteriores.

\section{Zeólitas}

A presença de zeólitas é bastante importante, pois pode interferir na permeabilidade e porosidade dos arenitos e, com isso, reduzir o potencial de fluxo do reservatório (Tucker, 1991).

A analcima foi encontrada na maioria das amostras das formações Caiuá, Pirapozinho e Santo Anastácio; todavia não foi encontrada nas formações Araçatuba e Adamantina, embora em trabalhos anteriores, como o de Brandt Neto et al. (1987) e Barison (2003), esse tipo de zeólitas tenha sido descrito.

Essas zeólitas podem ser associadas ao processo de dissolução de fragmentos vulcânicos presentes nos arenitos, fazendo com que ocorra uma mudança na composição química da água e precipitando zeólitas autigênicas. Morad (1991) sugere que as fontes de íons $\mathrm{Na}^{+}, \mathrm{Si}^{4+} \mathrm{e} \mathrm{Al}^{3+}$, necessárias para a formação desse cimento, são alterações de plagioclásio e vidros vulcânicos. Uma outra hipótese seria o processo de hidrotermalismo com contribuição química de rochas basálticas próximas, cristalizando-se preferencialmente nos poros e espaços intergranulares, conforme su-

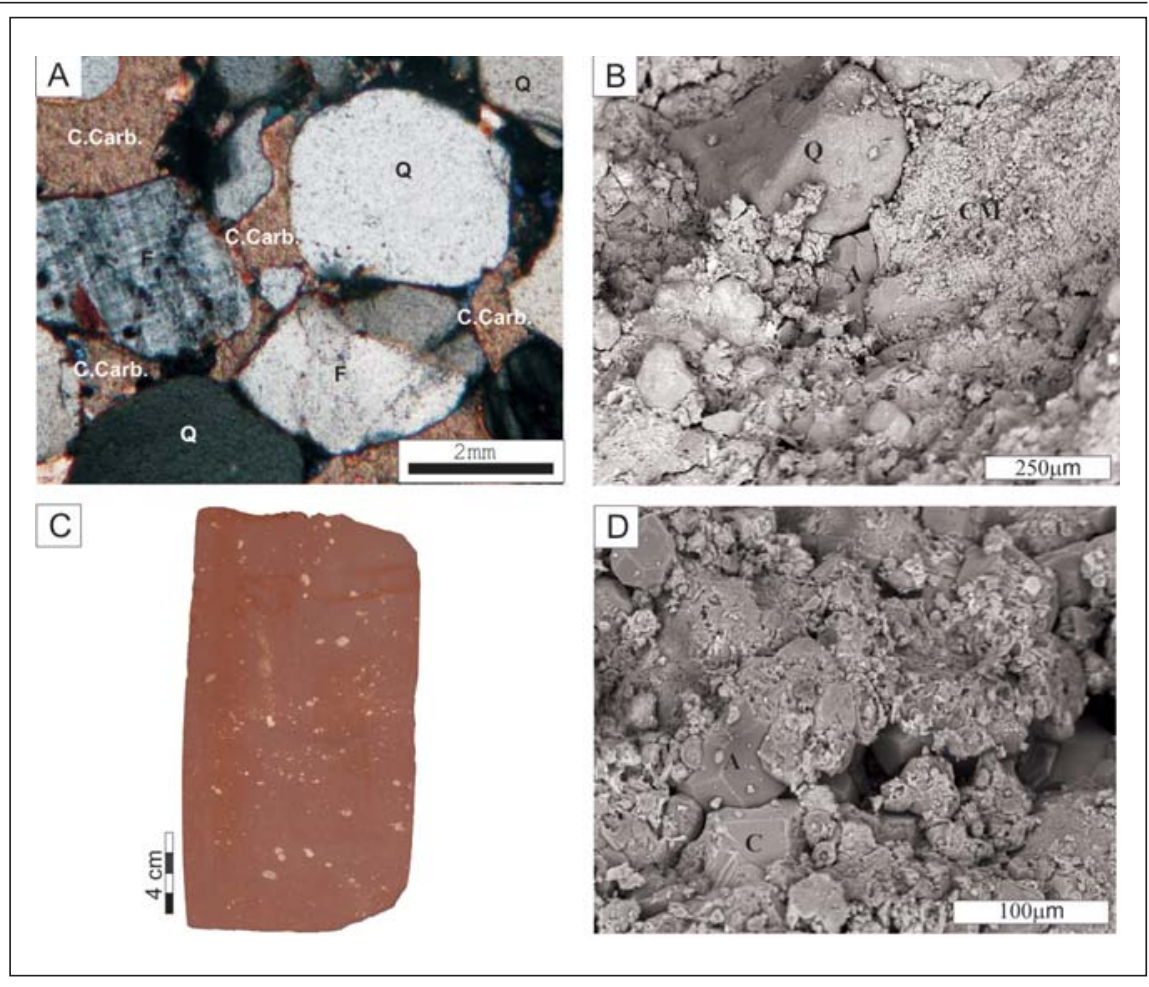

Figura 7 - A) Cimentação carbonática envolvendo grãos da Formação Caiuá (microscopia óptica, nicóis cruzados-aumento 10x). F=feldspato, $Q=q u a r t z o$, C.Carb.=cimentação carbonática. B) Cimentação carbonática micrítica (CM) envolvendo grãos de quartzo (Q) e analcima (A) da Formação Caiuá (Fotomicrografia de MEV). C) Arenito com calcretes na Formação Caiuá. D) Grão de calcita (C) e zeólita (A) da Formação Caiuá (Fotomicrografia de MEV).

gerido por Brandt Neto et al. (1987) e Barison (2003). Uma terceira hipótese seria atribuída à diagênese em sedimentos depositados em ambiente alcalino (e.g. playa-lake), em regiões áridas a semi-áridas, onde a concentração elevada de sódio causada pela evaporação pode provocar reações com argilominerais, formando zeólitas, principalmente a analcima (Morad, 1991).

As zeólitas aparecem na forma de cristais preenchendo poros (Figura 08A) e também em cavidades em grãos. Um outro tipo de zeólita observado nas amostras analisadas foi a natrolita, que aparece, com menor freqüência, apresentando aspecto fibroso (Figura 8-B).

A Tabela 1 apresenta análises químicas semiquantitativas, obtidas por meio de EDX (energia dispersiva), que mostram as composições químicas das zeólitas analcima e natrolita em rochas das formações Caiuá e Santo Anastácio, respectivamente.
A Tabela 2 apresenta a seqüência provável dos eventos diagenéticos observados na área de estudo.

\section{Conclusões}

As análises petrográficas dos arenitos do Grupo Bauru evidenciam grande semelhança de composição entre suas diferentes unidades, sendo classificados predominantemente como subarcóseos. Essa classificação, que difere de autores anteriores, pode relacionar-se com as amostras de arenitos, que, nesse estudo, foram coletadas em subsuperficie.

A porosidade do tipo intergranular predomina, sendo que a porosidade intragranular, produto de dissolução de minerais ou cimentos presentes nos arenitos, aparece com menor freqüência.

O estudo do arcabouço mineralógico revelou que o quartzo é o mineral mais abundante; os feldspatos mais freqüentes são os potássicos e, secundari- 


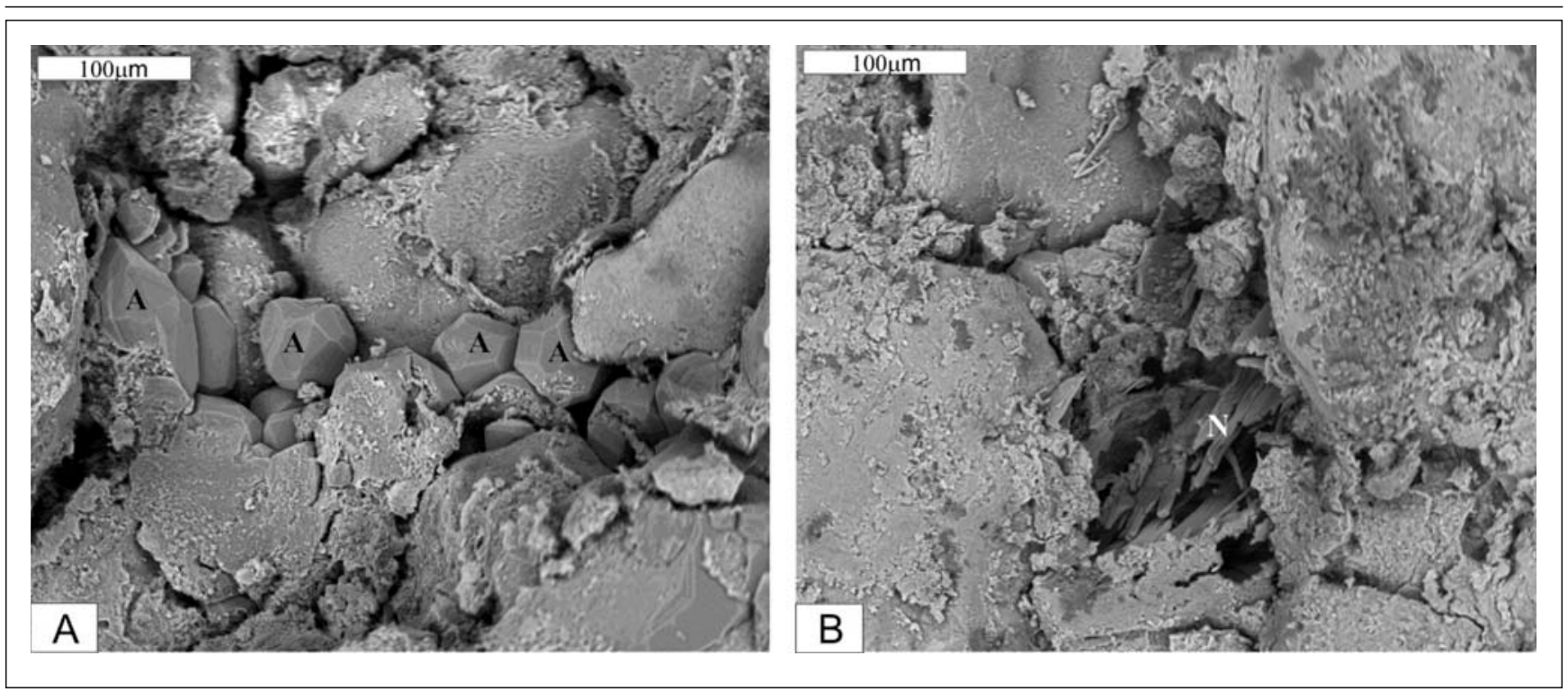

Figura 8 - A) Cristais de analcima (A) preenchendo os poros na Formação Caiuá. B) Natrolita (N) em cavidade em grãos de arenitos da Formação Santo Anastácio (Fotomicrografia de MEV).

Tabela 1 - Análises químicas semiquantitativas de zeólitas por microscopia eletrônica no ED-SEM (Energy Dispersive Scanning Electron Microscope). Au refere-se à metalização das amostras.

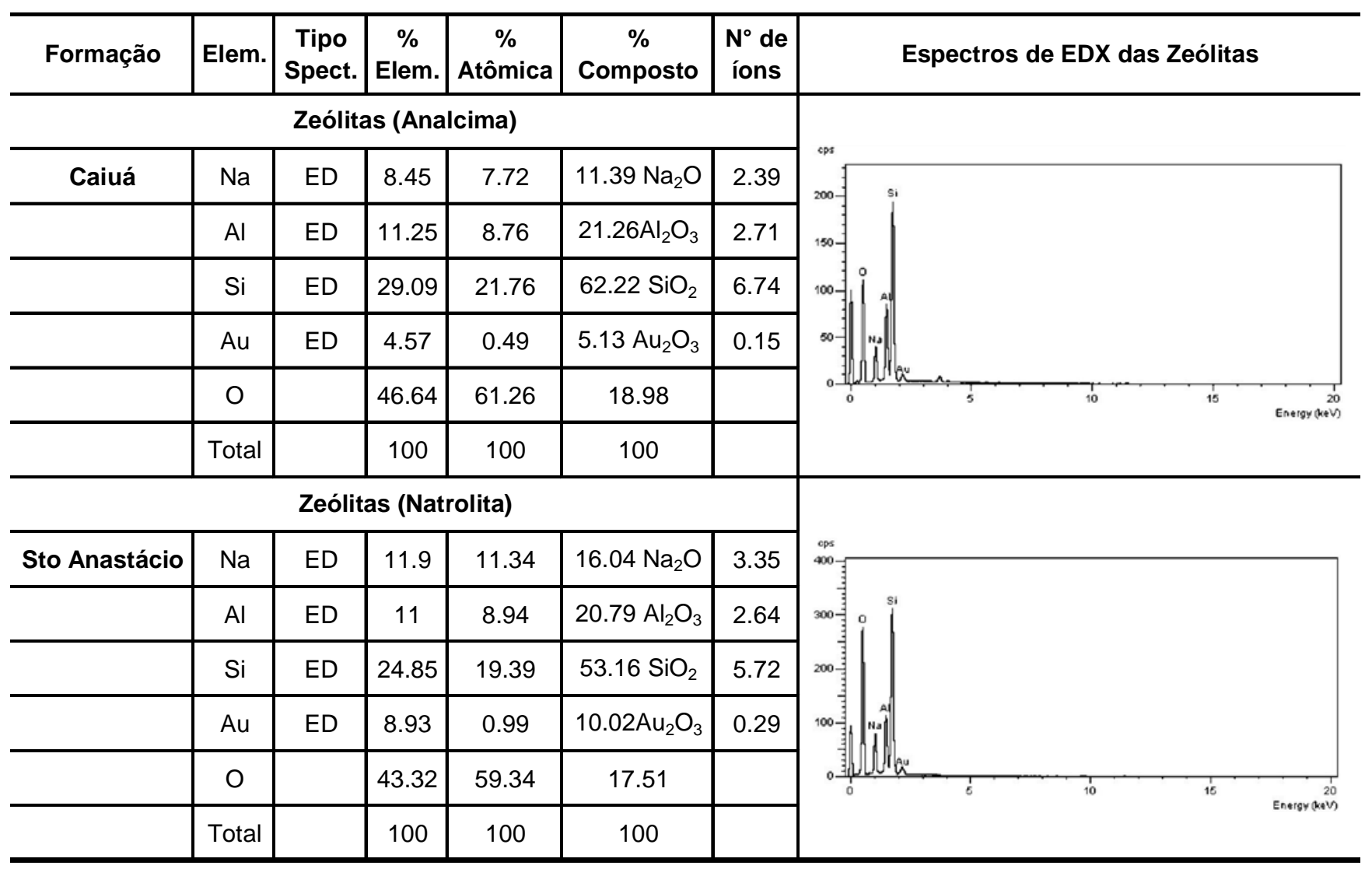

System resolution $=68 \mathrm{eV} ; \quad$ Quantitative method: ZAF (3 iterations); Analysed elements combined with: O (Valency: -2 ); Method: Stoichiometry Normalised results; Nos. of ions calculation based on 12 cations per formula. 
Marcia Regina Stradioto et al.

amente, os plagioclásios; a matriz é constituída predominantemente por argilominerais do tipo ilita e montmorilonita e mais raramente caulinita.

Os arenitos estudados foram submetidos à eodiagênese, abrangendo desde a fase precoce até a fase tardia. A seqüência diagenética observada compreende: dissolução de minerais pesados, fragmentos líticos e aluminossilicatos; cimentação por calcita microcristalina, formação de argilominerais, cimentação por calcita em mosaico ou poiquilotópica e cimentação por zeólitas.

\section{Agradecimentos}

Os Autores agradecem à CAPES pela bolsa de mestrado concedida à Marcia Regina Stradioto, ao Laboratório de Estudo de Bacias - LEBAC-DGA/ UNESP, Campus de Rio Claro, ao CNPq (Proc. 350983/97-6) e à FUNDUNESP, pelo suporte técnico e financeiro para elaboração desse artigo.

\section{Referências bibliográficas}

BATEZELLI, A., GOMES, N.S., PERINOTTO, J.A.J. Petrográfica e evolução diagenética dos arenitos da porção norte e nordeste da bacia Bauru (Cretáceo Superior). Revista Brasileira de Geociências, v. 35, n.3, p.311-322, 2005.

BATEZELLI, A., PERINOTTO, J.A.J., ETCHEBEHERE, M.L.C., FULFARO, V.J., SAAD, A.R. Redefinição litoestratigráfica da unidade Araçatuba e da sua extensão regional na bacia Bauru, Estado de São Paulo, Brasil. In: SIMPÓSIO CRETÁCEO BRASIL, 5 E SIMPÓSIO CRETÁCEO AMÉRICA DO SUL, 1. Serra Negra, Boletim, 1999. p.195-200.

BARISON, M.R. Estudo hidroquímico da porção meridional do Sistema Aqüífero Bauru no Estado de São Paulo. Rio Claro: Instituto de Geociência e Ciências Exatas, UNESP, 2003. 153p. (Tese de Doutorado em Geociências e Meio Ambiente).

BRANDT NETO, M., BARELLI, N., BARCHA, S.F., COIMBRA A.M. Ocorrência de analcima em sedimentos

Tabela 2 - Fases diagenéticas identificadas nas amostras de arenitos estudados.

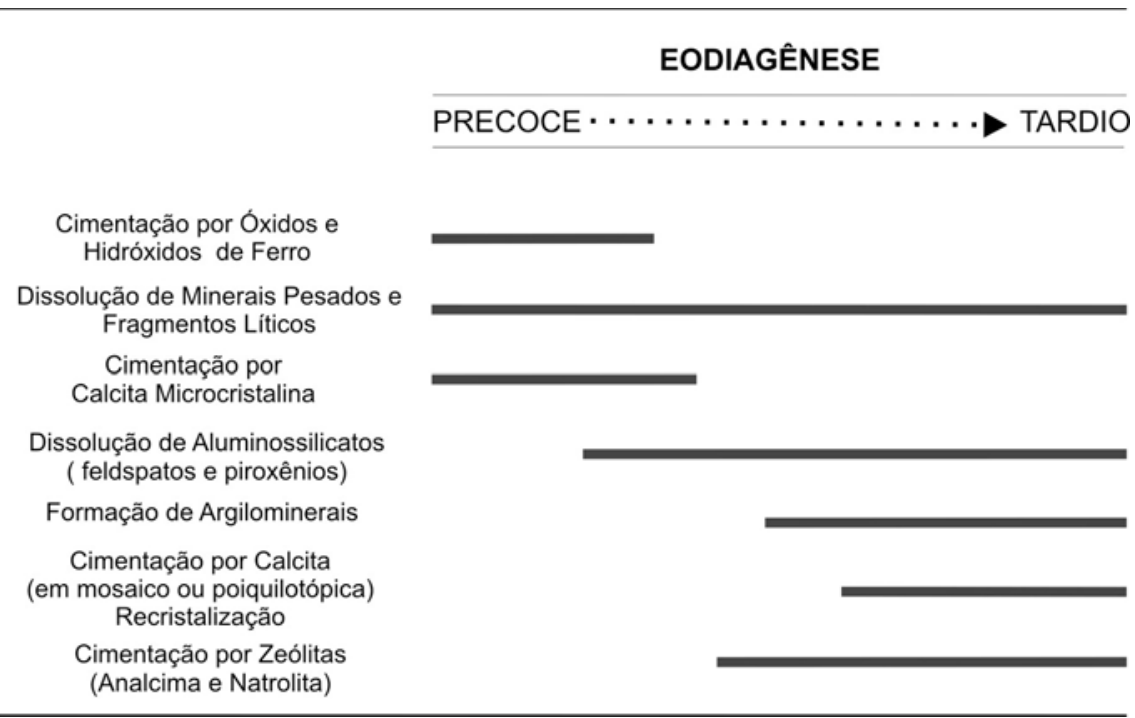

da Formação Adamantina em Macedônia (Estado de São Paulo), uma evidência de hidrotermalismo no Grupo Bauru. In: SIMPÓSIOREGIONAL DE GEOLOGIA, 6. Atas... Rio Claro: SBG/SP, 1987. v. 1, p.113-121.

COMPANHIA DE TECNOLOGIA DE SANEAMENTO AMBIENTAL CETESB. Uso das águas subterrâneas para abastecimento público no Estado de São Paulo. São Paulo: 1997. 48p.

CESERO, P., MAURO, L.M., DE ROS, L.F. Técnicas de preparação de lâminas petrográficas e de moldes de poros na PETROBRÁS. Boletim Geociências Petrobrás, 3, Rio de Janeiro, p.105-116, 1989.

DAEE (Departamento de Águas e Energia Elétrica). Estudo de águas subterrâneas, Regiões Administrativas 7 (Bauru), 8 (São José do Rio Preto) e 9 (Araçatuba), SP. São Paulo: DAEE, 1976. v. 1 e 2.

FOLK, R.L. Petrology of sedimentary rocks. Austin: Hemphill's, 1968. 182p.

INSTITUTO DE PESQUISAS TECNOLÓGICAS DO ESTADO DE SÃO PAULO - IPT. Mapa geológico do Estado de São Paulo, escala 1:500.000. São Paulo - SP: IPT, 1981. v. 1 e 2.

MORAD, S. Diagenesis of clastic sedimentary rocks. Uppsala: Department of Mineralogy and Petrology. Institute of Geology, Uppsala University, 1991. 287p.

PAULA E SILVA, F., CAVAGUTI, N. Nova caracterização estratigráfica e tectônica do Mesozóico na cidade de Bauru - SP. Geociências, v.13, n.1, p.83-99, 1994.

PAULA E SILVA, F., CHANG, H.K., CAETANO-CHANG, M. R. Perfis de referência do Grupo Bauru (K) no Estado de São Paulo. Geociências, v.22 (especial), p. 21-32, 2003.

PAULA E SILVA, F., CHANG, H.K., CAETANO-CHANG, M.R. Estratigrafia de subsuperfície do Grupo Bauru (K) no Estado de São Paulo. Revista Brasileira de Geociências, v.35, n.1, p.77-88, 2005.

PAULA E SILVA, F., CHANG, H.K., CAETANO-CHANG, M. R., STRADIOTO, M. R. Sucessão sedimentar do Grupo Bauru na região de Pirapozinho (SP). Geociências, v.25, n.1, p.17-26, 2006.

SOARES, P. C., LANDIM, P. M. B., FÚLFARO, V. J., SOBREIRO NETO, A. F. Ensaio de caracterização estratigráfica do Cretáceo no Estado de São Paulo: Grupo Bauru. Revista Brasileira de Geociências, v.10, n.3, p.177-185, 1980.

SUGUIO, K., FULFARO, V. J., AMARAL, G., GUIDORZI, L. A. Comportamentos estratigráfico e estrutural da Formação Bauru nas regiões administrativas 7 (Bauru), 8 (São José do Rio Preto) e 9 (Araçatuba) no Estado de São Paulo. In: SIMPÓSIO REGIONAL. GEOLOGIA, 1. Atas... São Paulo, 1977. p.231-247.

TUCKER, M. E. Sedimentary petrology: an introduction to the origin of sedimentary rocks. ( $2^{\text {th }}$ ed.). Oxford: Blackwell, 1991. $260 \mathrm{p}$.

WILSON, M.D. Reservoir Quality Assessment and Prediction in Clastic Rocks, SEPM Short Course 30, Tulsa, Oklahoma, 1994. 432p.

Artigo recebido em 31/10/2007 e aprovado em 29/05/2008. 